\title{
Examining AIS Software and Co-operative Performance in Malaysia
}

\author{
Mohd Hadzrami Harun Rasit *and Mohammad Azhar Ibrahim \\ Tunku Puteri Intan Safinaz School of Accountancy, Universiti Utara Malaysia
}

\begin{abstract}
Accounting information systems (AIS) is essential to process business data into useful information. Indeed, empirical evidence suggested that the use of AIS has a positive impact on firm performance. Previous studies were concentrating on small and medium-sized enterprises (SMEs) and public listed companies leaving a gap in the co-operative literature. Furthermore, the users of different types of AIS software that contribute towards improving the firm performance were not adequately explored. As such, this paper draws on the resource-based view (RBV) to examine the gap issue. Using mail questionnaire survey, data were collected from 120 co-operatives. Findings from this study suggest that commercial and developed-inhouse AIS software are mostly used by co-operatives. Also, the findings suggest that co-operatives performance is not associated with the types of AIS software used by the co-operatives. This study provides valuable insights into the implementation of AIS among Malaysian co-operatives, which has received little attention thus far from academic, governmental and professional bodies.
\end{abstract}

Keywords: Accounting Information Systems, Information Systems Resources, AIS Software, Resource-Based View, Co-Operative, Performance, Malaysia.

JEL Classification: O33, O43, M41

Paper Type: Research

\section{INTRODUCTION}

Accounting information system (AIS) ${ }^{1}$ is asserted to contribute towards improving the performance of business organisations. Empirical evidence suggested that the use of AIS

* Corresponding author: E-mail: hadzrami@uum.edu.my

${ }^{1}$ AIS is defined as computer-based systems that capture and process financial data (i.e. daily transactions) into useful information for decision making (Nicolaou, 2000). 
provides a significant impact on firm performance (Ismail \& King, 2005b; Kharuddin, Ashhari, \& Nassir, 2010; Kouser, Rana, \& Shahzad, 2011; Soudani, 2012). The use of AIS enables the organisation to process business data into useful information effectively and promptly. As a result, managers can make a sound business decision that will positively affect organisational performances. Studies on AIS involved various issues. They include AIS adoption (see Elbarrad, 2012; Edison, Manuere, Joseph \& Gutu, 2012; Mollanazari \& Abdolkarimi, 2012); AIS usage (see Ismail \& Zin, 2009); AIS roles (see Heidhues \& Patel, 2008) and AIS implementation (see Ismail \& King, 2005a) to name but a few. This signifies the importance of AIS to the world communities or business organisations, in particular. However, most of these studies were confined to investor-owned firms (IOFs) domain namely small and medium-sized enterprises (SMEs) and listed companies (see for example Bharadwaj, 2000; Ismail \& King, 2005; Karimi et al., 2007; Kharuddin et al., 2010; Kouser et al., 2011; Ravichandran \& Lertwongsatien, 2005; Salehi et al., 2012; Soudani, 2012). Studies on AIS in a co-operative environment, however, is found to be lacking (the study of King \& Shuker, 1991, is notably excluded). This could be because cooperative has not been a trendy research area as compared to SMEs and listed companies (Othman et al., 2012).

Co-operatives are regarded as an essential business organisation for their significant economic and social contribution (Harun \& Mahmood, 2012). They also have been highlighted by social philosophers and economists around the world as an essential mechanism for growth and development (Othman \& Kari, 2008). Indeed, cooperatives now are established in most of the world. They can be found either in developed countries of Canada, the United States and Europe or the developing countries such as Asia, Africa and South America. The co-operatives membership are recorded more than one billion people worldwide (ICA, 2013). Malaysia itself has more than seven million memberships which represent approximately twenty-five percent (25\%) of the population (MCSC, 2013). This indirectly indicates the support and confidence from global communities to the cooperative movement.

A review of the related literature suggests that co-operatives, Malaysia in particular, are displaying low performance. For instance, the statistic released by the Malaysia Cooperative Society Commission (MCSC) ${ }^{2}$ as of June 30,2016 , shows that nearly $50 \%$ of 13,247 co-operatives are operating at a loss. In addition, out of 13,247 co-operatives, $88 \%$ $(11,627)$ of them are categorised as micro ${ }^{3}$ co-operatives. This issue needs to be carefully addressed by looking into ways of improving the individual co-operative performance that will directly increase the performance of co-operative sector as a whole. The use of AIS could be an option. Indeed, some studies found that AIS usage contributes to organisation performance (Ismail \& King, 2005b; Kharuddin et al., 2010; Kouser, Awan, Gul-e-Rana, \& Shahzad, 2011; Salehi, Abedini, \& Rasouli, 2012; Soudani, 2012).

Theoretically, the Resource-Based View Theory (RBV) is used to investigate the sources of sustained competitive advantage for firms (Barney, 1991). The RBV is built upon two assumptions. First, resources are heterogeneous; in consequence, competing firms can own different bundles of resources. Second, resources are immobile; differences in resources can be subject to sustainability (Barney, 1991). Firms are known to have various resources. However, not all resources hold the potential for sustained competitive advantage. The RBV suggests that a resource must display four attributes to be a potential source of competitive advantage (Barney, 1991). These attributes are valuable, rare, imperfectly imitable and non-substitutable. A resource is valuable when it can assist firm in formulating and implementing strategies to become more effective and efficient.

\footnotetext{
2 MCSC is the governing body of co-operatives in Malaysia.

${ }^{3}$ Co-operatives with annual turnover of less than RM200,000.
} 
A resource is considered as rare when it is scarce and not available to another competitor firm. Meanwhile, a resource that is imperfectly imitable when it is impossible for other competitor firms to acquire. For example, a valuable resource is possessed by only a single firm. On the other hand, a non-substitutable resource refers to a resource that is difficult to replicate and exchanged with other alternatives. Firms that own valuable and rare resources could obtain a short-term competitive advantage. In sustaining a longterm competitive advantage, firms must be able to safeguard their resources from replication, transfer, or substitution (Wade \& Hulland, 2004). In general, resources refer to all assets, capabilities, processes, firm attributes, information, and knowledge that are possessed by a firm that are useful to detect and respond to market opportunities and threats (Barney, 1991; Wade \& Hulland, 2004). In the context of IS, IS resources refer to the combination of IT assets and IT capabilities (Aral \& Weill, 2007).

This paper reports and discusses the results of a study which investigates the use of AIS software in the context of Malaysian co-operatives. The objectives of this paper are two prongs. First, to document the types of AIS software used by co-operatives. Second, to examine the relationship between the types of AIS software used and performance of the co-operatives. Based on the fact that previous studies in AIS were confined to SMEs and listed companies, this paper contributes to AIS literature by extending the research into co-operatives domain. In addition, the findings from this study would provide important insights into the current profile of AIS software usage among Malaysian co-operatives. The information may assist relevant government agencies in preparing a more comprehensive plan for co-operatives. Also, considering AIS potential in assisting management function of co-operatives, this paper is could be used as a reference for cooperatives' management in choosing the suitable AIS software for their daily business operation.

This paper is organised as follows. The next section, Section 2, is a review of related literature. The methodology is presented in Section 3, followed by results and discussion in Section 4. A conclusion in Section 5 concludes this paper.

\section{LITERATURE REVIEW}

\subsection{Co-operatives}

A co-operative is defined by the International Co-operative Alliance (ICA) as "...an autonomous association of persons united voluntarily to meet the common economic, social, and cultural needs and aspirations through a jointly-owned and democratically controlled enterprise" (ICA, 2014). To further describing co-operatives, Othman \& Kari (2008) underlined three main characteristics of a co-operative. Firstly, a co-operative has to be a self-governing non-government organisation. Secondly, a co-operative need to be owned and controlled by the members themselves; and lastly, its objectives are to improve the economic and social development of its members. These characteristics are respectively referred to by Katz (1998) as user-control and democratic principle; userowner principle and user-benefit principle. The user-control and democratic principle stress on the equal rights and eligibility of members to take part in the co-operatives' selfautonomy. The user-owner principle emphasises the member's responsibility provide equity to co-operatives while being the co-operatives' suppliers or customers at the same time. Meanwhile, the user-benefit principle requires co-operatives to sustain economic efficiency and profitability or the social interests of the members. 


\subsection{AIS Related Studies}

Previous studies suggested that the use of AIS provides a significant impact on organisation's performance. For example, Salehi et al. (2012) examined the impact of AIS on the financial performance of 118 firms listed in Iran. They found that firms with excellent AIS performance have a positive effect on firm performance. In another study, Soudani (2012) studied the performance impact of AIS among 74 listed companies in the United Arab Emirates. He found that AIS has a significant effect on firms' financial performance. Additionally, Kouser et al., (2011) investigated the effects of AIS on the profitability of 66 public listed companies in Pakistan from 2005 to 2009. Consistent with previous studies, they also found that AIS has a significant influence on the companies' profitability. Grande et al. (2011) examined the performance impact of AIS among 74 SMEs in Spain. They found a positive impact of AIS on two aspects, namely banking and fiscal management, and performance indicators.

In the context of Malaysia, Ismail and King (2005b) surveyed 310 manufacturing SMEs to examine the performance impact of the alignment of AIS capacity with AIS requirements. They found that the performance of with high AIS alignment group is better than low AIS alignment group. In a recent study, Kharuddin, Ashhari \& Nassir (2010) investigated the relationship between AIS and performance of Malaysian SMEs. Using panel data for the period of five years (i.e. 2004 to 2008 inclusive), they found that SMEs adopting accounting information system show significant improvement in performance compared to non-adopters. Although substantial studies have shown that AIS has a significant impact on firm performance, most studies do not adequately explain the types of AIS software which contribute to improving co-operatives performance.

\section{METHODOLOGY}

\subsection{Data Collection}

A questionnaire survey was conducted to collect the data. The unit of analysis of this study was the organisation level. The target population in this study was the co-operatives that are registered with the MCSC. The statistics published in the MCSC website show that the total of 12,493 co-operatives registered with the MCSC as at June 2015. However, this study excludes micro co-operatives (total of 10,920 co-operatives) since the majority of micro co-operatives are relatively very small with less capital. There is a high possibility that they do not use AIS in their operation. All in all, the total of 1,573 co-operatives is the final population of the study comprising large, medium and small co-operatives.

The sampling frame is extracted from the directory of cooperatives in Malaysia. The directory is acquired from The Statutory and Registration Department of Malaysia Cooperative Commission as suggested by Harun and Mahmood (2012). The total of 1,573 co-operatives from large, medium and small clusters were included in the sampling frame. For a population frame between 1,500 - 2,000 firms, Bartlett, Kotrlik, and Higgins, (2001) suggested a minimum samples size of 112. In order to ensure a valid number of response received, 1000 co-operatives was selected for this study due to a low response rate been anticipated.

This study utilised simple random sampling as a sampling technique. A total of 1000 co-operatives across Malaysia were randomly selected from the MCSC directory. Following previous works (i.e. Aral \& Weill, 2007; Chen, 2012; Zhang, 2007), the questionnaires were mailed to the manager of several co-operatives using the respondents' correspondence addresses as provided in the directory. The managers were considered as the most crucial likely person that can furnish information since they are 
directly involved in daily activities of the cooperative (Harun \& Mahmood, 2012). A soft reminder letter was mailed after two weeks to all the respondents reminding them to complete and return the questionnaires. A total of 161 responses were received resulting in a response rate of $16 \%$. Out of these responses, 41 were discarded due to incomplete data, leaving 120 responses in the final analysis, thus meet the minimum samples size been suggested.

\subsection{Measures}

The cooperative performance was measured using subjective measures of market-based performance and operating performance adopted from Ravichandran and Lertwongsatien (2005). Since the financial data of the respective co-operatives were not publicly available, this study followed Dess and Robinson (1984) that suggested subjective perception data of organisational performance might be considered in the absence of objective data. Furthermore, managerial assessments of company performance are highly correlated with objective performance indicators (Dess \& Robinson, 1984; Venkatraman \& Ramanujam, 1986).

Operating performance is measured using a four-item scale that assesses the extent to which the profitability, productivity, and financial performance exceeded those of their competitors for the past three years (i.e., 2013-2015). Market-based performance is measured using a three-item scale that assesses the success of the co-operative in entering new markets and in bringing new products and services to the market for the past three years (i.e., 2013-2015). All items were measured using Likert scales ranging from 1 (strongly disagree) to 5 (strongly agree).

\section{RESULTS AND DISCUSSION}

The Statistical Package for Social Science (SPSS) version 18.0 was used to analyse the questionnaire data. Descriptive statistics were conducted to report the frequencies, means score and standard deviations of the demographic data, group cohesiveness and organisational performance. Chi-square test of independent was used to test the relationships between type of AIS software used and co-operative performance.

Table 1 presents the profile of responding co-operatives regarding co-operatives' cluster, business function, type of AIS and no. of years of AIS usage. Small cluster cooperatives dominated the sample with $42 \%$ of the respondents followed by medium and large cluster $(35 \%$ and $23 \%$ respectively. When it concerns business function of the cooperatives, the highest respondents are agriculture $(28 \%)$ and finance $(28 \%)$. With regards the type of AIS used, nearly half of the respondents $(44 \%)$ used commercial software followed by in-house-developed software (38\%). When it concerns the no. of years of AIS usage, $38 \%$ of the respondents have been using AIS for more than ten years. Meanwhile, $21 \%, 18 \%$ and $23 \%$ of the respondents have been using AIS for about 6 to 10 years, 3 to 5 years and less than 3 years respectively. 
Table 1. Profile of Responding Co-operatives

\begin{tabular}{llcc}
\hline Co-operative Information & Category & No. & Percentage \\
\hline Cluster & Small & 50 & 42 \\
& Bedium & 42 & 35 \\
& Big & 28 & 23 \\
Business Function & Banking & 4 & 3 \\
& Industrial & 33 & 28 \\
& Construction & 6 & 5 \\
& Services & 1 & 8 \\
& Finance & 11 & 9 \\
& Housing & 33 & 28 \\
& Consumer & 2 & 2 \\
Type of AIS & Transportation & 14 & 12 \\
& & 16 & 13 \\
& In-house-developed software & 45 & 38 \\
& Commercial software & 53 & 44 \\
No. of years using AIS & Customised software & 17 & 14 \\
& Others* & 5 & 4 \\
& & & 23 \\
& Less than 3 years & 28 & 18 \\
\hline
\end{tabular}

${ }^{*}$ Co-operatives outsource the used of AIS software to a third party

Table 2 displays the type of AIS used according to co-operatives cluster. In general, of all the type of AIS, commercial and in-house-developed software appear to be ranked first and second respectively in the ranking of AIS software used by co-operatives. Analysis of the software usage according to co-operatives' cluster was further conducted. When it concerns the small cluster, about $50 \%$ of the respondents used an in-house-developed AIS software and about $40 \%$ of them used commercial software (i.e. UBS, Mr Accounting, MYOB, and APLUS). With regards to medium cluster, relatively similar number of respondents used in-house-developed and commercial software (40\% and 38\% respectively) in their co-operatives. On the contrary, commercial AIS software dominated the type of AIS usage (61\%) in the big cluster co-operatives. Further analysis using Pearson Chi-Square shows that there is a significant association between the types of AIS software used and co-operatives clusters (Chi-square=14.744, df=6, $p<0.05$ ).

Table 2. Type of AIS according to co-operative cluster

\begin{tabular}{lcccccc}
\hline \multirow{2}{*}{ Type/Cluster } & \multicolumn{2}{c}{ Small } & \multicolumn{2}{c}{ Medium } & \multicolumn{2}{c}{ Big } \\
\cline { 2 - 7 } & No. & $\%$ & No. & $\%$ & No. & $\%$ \\
\hline In-house-developed & 25 & 50 & 17 & 40 & 3 & 11 \\
Commercial & 20 & 40 & 16 & 38 & 17 & 61 \\
Customised & 3 & 6 & 7 & 17 & 7 & 25 \\
Others & 2 & 4 & 2 & 5 & 1 & 4 \\
Total & 50 & 100 & 42 & 100 & 28 & 100 \\
\hline
\end{tabular}

Table 3 tabulates types of AIS used by co-operatives and their performance. In the earlier discussion, co-operatives performance was measured using a seven-item of Likert scales ranging from 1 (strongly disagree) to 5 (strongly agree). Co-operatives are considered under high-performance group if the value of total performance is exceeding its mean value (i.e. mean value $=21$ ). In total, the number of low and high-performance cooperatives is relatively similar (49\% and $51 \%$ respectively). Further analysis of highperformance co-operatives shows that co-operatives which used commercial and inhouse-developed AIS software are ranked first and second (39\% and $38 \%$ respectively). 
However, analysis using a Chi-Square test for independence suggest weak evidence of a relationship between co-operatives performance and the types of AIS software used (Chisquare $=7.027, d f=3, p=0.071$ ). Since the $p$-value of 0.071 is larger than the alpha value of 0.05 , the result indicates that there is no significant association between co-operatives performance and the types of AIS software used.

Table 3. Types of AIS used and co-operative performance

\begin{tabular}{|c|c|c|c|c|c|c|c|c|c|c|}
\hline & \multicolumn{2}{|c|}{$\begin{array}{l}\text { In-house- } \\
\text { developed }\end{array}$} & \multicolumn{2}{|c|}{ Commercial } & \multicolumn{2}{|c|}{ Customised } & \multicolumn{2}{|c|}{ Others } & \multicolumn{2}{|c|}{ Total } \\
\hline & No. & $\%$ & No. & $\%$ & No. & $\%$ & No. & $\%$ & No. & $\%$ \\
\hline Low Performance & 22 & 37 & 29 & 49 & 4 & 7 & 4 & 7 & 59 & 49 \\
\hline High Performance & 23 & 38 & 24 & 39 & 13 & 21 & 1 & 2 & 61 & 51 \\
\hline Total & 45 & 38 & 53 & 44 & 17 & 14 & 5 & 4 & 120 & 100 \\
\hline
\end{tabular}

\section{CONCLUSION}

This paper examines the profiles of AIS software usage and the relationship between different types of AIS software usage and co-operative performance. When it concerns the former, the commercial and in-house-developed AIS software is found to be mostly used by co-operatives. Also the in-house-developed and commercial AIS software are mostly used in small and medium clusters co-operatives. On the contrary, most of the big cluster co-operatives prefer to use customised AIS software for their organisation. As for the latter, we found that high-performance co-operatives have been using commercial and in-house-developed AIS software. However, no significant relationship between types of AIS software usage and co-operative performance were reported. This suggests that cooperative performance is not associated with the types of AIS software used by the cooperatives. The possible explanation is that AIS software used by the co-operatives is generic. As mentioned earlier, the RBV postulates that a resource (i.e. AIS software) must be valuable, rare, imperfectly imitable and non-substitutable to contribute towards performance (Barney, 1991). However, given the types, AIS software used by most cooperatives are in-house developed and commercial AIS software, they do not meet these criteria. For example, the software is not rare because it is available to competitors. Also, it is imitable because it is possible for other competitor co-operatives to acquire. Additionally, the software is easy to replicate and exchanged with other alternatives.

The findings of this study are subject to limitations thus need to be read with caution. Firstly, the findings are based on a modest sample size of 120 responses. Future research is therefore suggested to employ a larger sample size to allow generalisation of findings. Secondly, the study is confined to co-operatives that have been using AIS software. Future research may include both co-operatives that used and do not use AIS software. This will enable comparison of the relationships with performance between these two different groups.

\section{REFERENCES}

Aral, S., \& Weill, P. (2007). IT assets, organisational capabilities, and firm performance: How resource allocations and organisational differences explain performance variation. Organization Science, 18(5), 763-780.

Barney, J. (1991). Firm resources and sustained competitive advantage. Journal of Management, 17(1), 99-120.

Bartlett, J. E., Kotrlik, J. W., \& Higgins, C. (2001). Organizational research: Determining appropriate sample size for survey research. Information Technology, Learning, and Performance Journal, 19(1), 43-50. 
Bharadwaj, A. S. (2000). A resource-based perspective on information technology capability and firm performance: An empirical investigation. MIS Quarterly, 24(1), 169-196.

Chen, J.-L. (2012). The synergistic effects of IT-enabled resources on organisational capabilities and firm performance. Information \& Management, 49(3-4), 142-150. http://doi.org/10.1016/j.im.2012.01.005

Dess, G. G., \& Robinson, R. B. (1984). Measuring organizational performance in the absence of objective measures: The case of the privately-held firm and conglomerate business unit. Strategic Management Journal, 5(3), 265-273. http://doi.org/10.1002/smj.4250050306

Edison, G., Manuere, F., Joseph, M., \& Gutu, K. (2012). Evaluation of factors influencing adoption of accounting information system by small to medium enterprises in Chinhoyi. Interdisciplinary Journal Of Contemporary Research In Business, 4(6), 1126-1141.

Elbarrad, S. S. (2012). Rationalizing the Investment Decision in Computerized Accounting Information Systems - An Applied Study on Saudi Arabian Companies. International Journal of Economics and Finance, 4(8), 42-59. http://doi.org/10.5539/ijef.v4n8p42

Grande, E. U., Estébanez, P., \& Colomina, M. (2011). The impact of accounting information systems (AIS) on performance measures: Empirical evidence in Spanish SMEs. The International Journal of Digital Accounting Research, 11, 25-43. http://doi.org/10.4192/1577-8517-v11

Harun, M. M. Z., \& Mahmood, R. (2012). The relationship between group cohesiveness and performance: An empirical study of cooperatives movement in Malaysia. International Journal of Cooperative Studies, 1(1), 15-20.

Heidhues, E., \& Patel, C. (2008). The role of accounting information in decision-making processes in a German dairy cooperative. In Emerging Issues in International Accounting Conference, China, June 2008 (pp. 1-45).

ICA. (2013). Co-operative facts \& figures | ICA: International Co-operative Alliance. Retrieved September 9, 2013, from http://ica.coop/en/whats-co-op/co-operative-facts-figures

ICA. (2014). Co-operative identity, values \& principles I ICA: International Co-operative Alliance. Retrieved March 31, 2014, from http://ica.coop/en/whats-co-op/co-operativeidentity-values-principles

Ismail, N. A., \& King, M. (2005a). A model for implementing accounting information systems in small and medium-sized enterprises. Malaysian Management Journal, 9(1 \& 2), 71-89.

Ismail, N. A., \& King, M. (2005b). Firm performance and AIS alignment in Malaysian SMEs. International Journal of Accounting Information Systems, 6(4), 241-259. http://doi.org/10.1016/j.accinf.2005.09.001

Ismail, N. A., \& Zin, R. M. (2009). Usage of Accounting Information among Malaysian Bumiputra Small and Medium Non-Manufacturing Firms. Journal of Enterprise Resource Planning Studies, 2009, 1-7.

Karimi, J., Somers, T. M., \& Bhattacherjee, A. (2007). The role of information systems resources in ERP capability building and business process outcomes. Journal of Management Information Systems, 24(2), 221-260. http://doi.org/10.2753/MIS07421222240209

Katz, J. P. (1998). Managerial behaviour and strategy choices in agribusiness cooperatives. Agribusiness, 13(5), 483-495.

Kharuddin, S., Ashhari, Z. M., \& Nassir, A. M. (2010). Information system and firms' performance: The Case of Malaysian Small Medium Enterprises. International Business Research, 3(4), 28-35.

King, R. P., \& Shuker, I. G. (1991). Information system adoption and use in local cooperatives. Journal of Agricultural Cooperation, 6, 54-65.

Kouser, R., Awan, A., Gul-e-Rana, \& Shahzad, F. A. (2011). Firm size, leverage and profitability: Overriding impact of accounting information system. Business and Management Review, 1(10), 58-64. Retrieved from http://www.businessjournalz.org/bmr

Kouser, R., Rana, G. e, \& Shahzad, F. A. (2011). Determinants of AIS Effectiveness: 
Assessment thereof in Pakistan. International Journal of Contemporary Business Studies, 2(12), 6-21. Retrieved from http://www.akpinsight.webs.com

MCSC. (2013). Official Portal Suruhanjaya Koperasi Malaysia. Retrieved August 21, 2013, from http://www.skm.gov.my/en/sejarah-gerakan-koperasi1

Mollanazari, M., \& Abdolkarimi, E. (2012). The Effects of Task, Organization and Accounting Information Systems Characteristics on the Accounting Information Systems Performance in Tehran Stock Exchange. International Journal of Innovation, Management and Technology, 3(4).

Nicolaou, A. I. (2000). A contingency model of perceived effectiveness in accounting information systems: Organizational coordination and control effects. International Journal of Accounting Information Systems, 1(2), 91-105.

Othman, A., \& Kari, F. (2008). Enhancing co-operative movement to achieve Malaysia' s development goals. Paper Presented at the ICA Research Conference: "The Role of CoOperatives in Sustaining Development and Fostering Social Responsibility," Riva Del Garda, Trento, Italy, 1-39.

Othman, A., Kari, F., Jani, R., \& Hamdan, R. (2012). Factors Influencing Cooperative Membership and Share Increment: An Application of the Logistic Regression Analysis in the Malaysian Cooperatives. World Review of Business Research, 2(5), 24-35.

Ravichandran, T., \& Lertwongsatien, C. (2005). Effect of information systems resources and capabilities on firm performance: A resource-based perspective. Journal of Management Information Systems, 21(4), 237-276.

Salehi, M., Abedini, B., \& Rasouli, A. (2012). Association of accounting information system and companies' performance: Iranian evidence. Archives Des Sciences, 65(7), 93-103.

Soudani, S. N. (2012). The Usefulness of an Accounting Information System for Effective Organizational Performance. International Journal of Economics and Finance, 4(5), 136145. http://doi.org/10.5539/ijef.v4n5p136

Venkatraman, A. N., \& Ramanujam, V. (1986). Measurement of business performance in strategy research : A comparison of approaches. The Academy of Management Review, 11(4), 801-814.

Wade, M., \& Hulland, J. (2004). Review: The resource-based view and information systems research: review, extension, and suggestions for future research. MIS Quarterly, 28(1), 107-142.

Zhang, M. J. (2007). Assessing the performance impacts of information systems from the resource-based perspective: An empirical test of the indirect effect of the IS. Journal of Business Strategies, 24(2), 141-164. 